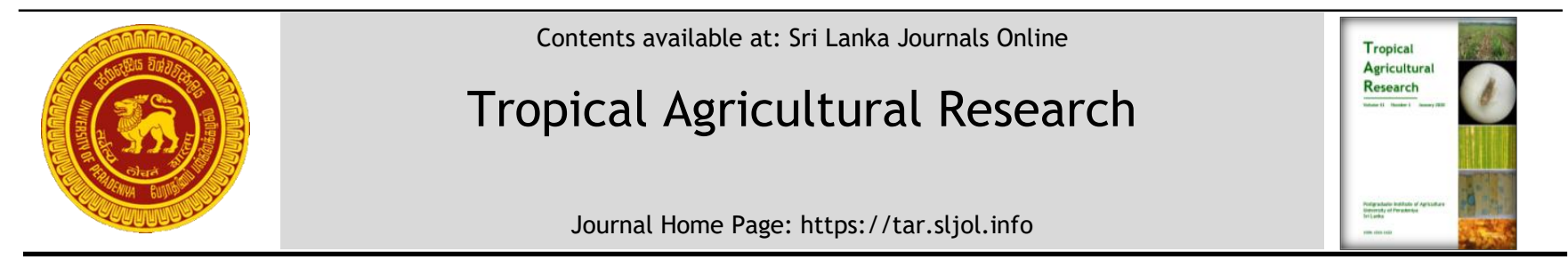

\title{
Relationship between Management Practices and Calf Welfare in Mid- Country Dairy Farms in Sri Lanka
}

\author{
W.P.C.G. Weerasinghe ${ }^{1}$, E.Rajapaksha ${ }^{2}$, W.W.D.A. Gunawardena ${ }^{3}$ and T.S. Samarakone ${ }^{1 *}$ \\ ${ }^{1}$ Department of Animal Science, Faculty of Agriculture, University of Peradeniya, Sri Lanka \\ ${ }^{2}$ Department of Veterinary Clinical Science, Faculty of Veterinary Medicine and Animal Science, University of Peradeniya, \\ Sri Lanka \\ ${ }^{3}$ Department of Animal Science, Faculty of Agriculture, University of Ruhuna, Sri Lanka.
}

\section{ARTICLE INFO}

\section{Article history:}

Received: 16 August 2019

Accepted: 24 October 2019

Available online: 01 December 2019

\section{Keywords:}

Calf management

Dairy farmers

Risk factors

Welfare

\section{Citation:}

Weerasinghe, W.P.C.G., Rajapaksha, E., Gunawardena, W.W.D.A. and Samarakone, T.S. (2020) Relationship between Management Practices and Calf Welfare in Mid-Country Dairy Farms in Sri Lanka. Tropical Agricultural Research, 31(1): 103-113.

DOI: http://doi.org/10.4038/tar.v31i1.8347

Weerasinghe, W.P.C.G. (iD

https://orcid.org/0000-0002-8433-9372

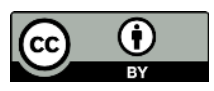

*Corresponding author: thusiths@pdn.ac.lk

\section{ABSTRACT}

There is an emerging trend towards appreciating welfare of farm animals in Sri Lanka. A survey was conducted covering 182 farms in Mid-Country, Sri Lanka to identify management-related risk factors that may affect welfare of dairy calves. A total of 217 calves were monitored where majority were Jersey (54.4\%) and Friesian (43.9\%) crosses. The management-related risk factors identified include, not practicing naval disinfection for new-borns (100\%), not using calving pens (100\%), absence of calf pen (96.2\%), dam-fed colostrum (99.5\%), high mortality (28.0\%), high prevalence of hock wounds (83.4\%) and diseases $(80.2 \%)$. Concrete/cement was the prominent flooring category (90.1\%) which causes unfriendly footing as indicated by hoof damageable (45.6\%), slippery (75.8\%), and unclean (40.7\%) floor conditions. The hoof damageable floors considerably increased hoof temperature $(\mathrm{P}<0.05)$ whereas slippery and dirty floors positively $(\mathrm{P}<0.05)$ contributed to the prevalence and severity of hock wounds by $31.1 \%$ and $17.2 \%$, respectively. Attitude of stockperson varied with the age where youths (19-30 years) concerned more about proper access to concentrate $(61.0 \%)$, immediate calf-dam separation $(20.2 \%)$ and proper age of weaning (58.4\%) than adults (31-65 years) and seniors ( $>65$ years). Welfare of male calves was satisfied with appropriate weaning age (3.8 \pm 1.4 months), concentrate supplement $(0.55 \pm 0.25 \mathrm{~kg})$, attending to health problems $(96.5 \%)$ and selling after six months of age $(89.6 \%)$. However, both female and male calves were underweight for their corresponding age. The findings emphasized that increasing the awareness on appropriate calf management practices is needed for achieving better results in raising calves into well-grown cattle. 


\section{INTRODUCTION}

The knowledge of the relationship between calf management practices and welfare is crucial for raising a new-born calf to a productive dairy cow. Quality of calf rearing impinges on welfare of calves. Poor management practices contribute to risk conditions such as vulnerability to diseases, failing to gain weight, mortality and loss of production (Weary, 2001).

Animal welfare is widely recognized as an essential component of the social pillar of sustainability in the dairy industry (Keyserlingk et al., 2009). Some of the most decisive areas of the welfare of dairy calves include the routine practices of care of newborn calf, the fate of male calves, time of cowcalf separation, when and how food and water is provided, housing facilities for calves, paininflicting procedures, (Flower \& Weary 2001). Appreciation of those routine management and welfare practices of dairy calves remains in very low level in Sri Lanka (Bandara et al., 2015). Prior to any intervention in increasing awareness of farmers on these aspects, as the initial step, the present situation of such practices need to be identified. In the current study, dairy cattle farms in Mid-Country, Sri Lanka was surveyed to assess information regarding calf rearing practices that could hinder dairy calf welfare.

\section{METHODOLOGY}

\section{Selection and description of Herds}

The survey was conducted in 182 dairy farms $(4.5 \pm 2.7$ herd size and $10.7 \pm 4.7 \mathrm{~L} /$ day/ farm) distributed in Mid-Country, Sri Lanka to gather information on calf management practices and welfare issues. Farms were randomly selected and a total of 217 claves were observed. The cows were kept in tie-stall housing system which is the type of housing used by $95 \%$ of dairy farms in Mid-Country, Sri Lanka (DAPH, 2009).

\section{Collection and description of Data}

A questionnaire was developed in accordance with United State National Animal Monitoring System (NAHMS): General Dairy Management Questionnaire- 2014 (USDA-APHIS, 2014), Dairy Heifer Raiser 2011 (USDA-NAHMS, 2011) and Codes of Recommendations for Welfare of Livestock: Cattle (DEFRA-2003). The questionnaire was pre- and time-tested before administered and the information was gathered with face to face interview with the farmer and recording necessary qualitative measurements on cow-based and shed based parameters.

The questionnaire consists of nine categories of management practices such as calving management and care of new-born, colostrum feeding, calf-dam separation, painful procedures, calf feeding, weaning, housing management, calf health management and calf handling. Close- and open-ended questions were included in the questionnaire. The rating scale (for example, 1- Bad, 2- Good and 3 Better cleanness of calf) and grouping (for example, youth (18-30 years), adult (31-65 years), senior ( $>65$ years) were followed to ensure the homogeneity of data reduce the subjectivity.

All four legs of 217 calves were captured using FLIR T420 Infrared Thermography (IRT) camera to evaluate hock wounds using high temperature generated by wounds. These thermal images were analyzed to calculate the number of wounds, the temperature of wounds, average hoof temperature and average skin temperature.

\section{Assessing of Welfare Attitude of Farmers}

Welfare attitudes of each farmer were evaluated using a scoring based system (Table 1 ), for both farm and farmer based characters. 


\section{Statistical Analysis}

Individual questionnaires were observed carefully to remove outliers and statistical analysis was conducted using SPSS 23.0 version. Descriptive statistics were calculated to describe farm characteristics and calf management practices. Thermal images were analysed in FLIR tools+ $₫$ software and white colour areas which indicated higher temperature than other areas were considered as a wound. Number of wounds per cow was grouped into four categories according to its severity ( 1 -No wound 10 wound), 2 - Less wounded (0-3 wounds), 3 More wounded (3-10 wounds), 4 - Severely wounded ( $>10$ wounds)).

Relationship between farm characteristic and management practices with welfare issues of calves were statistically identified using Crosstabs/ Fisher's exact test, Mann-Whitney U-test and Correlation by Pearson/Spearman rank coefficient.

Table 1: Scoring system for assessing of welfare attitude of farmers

\begin{tabular}{|c|c|c|c|}
\hline Farm-based characters & & Farmer-based characters & \\
\hline Character & Mark & Character & Mark \\
\hline Providing sufficient space & $(+)$ & $\begin{array}{l}\text { No hitting, kicking or use of } \\
\text { electric pods for calf handling }\end{array}$ & $(+)$ \\
\hline Easiness of feed access & $(+)$ & Back rest on the calf when talking & $(-)$ \\
\hline Water Availability & $(+)$ & Better welfare knowledge & $(+)$ \\
\hline $\begin{array}{l}\text { Clean flooring for better } \\
\text { resting time }\end{array}$ & $(+)$ & $\begin{array}{l}\text { Good knowledge of farmer about calf } \\
\text { nutrition }\end{array}$ & $(+)$ \\
\hline $\begin{array}{l}\text { Protection from other } \\
\text { animal (dog) }\end{array}$ & $(+)$ & Better attention on calf caring & $(+)$ \\
\hline
\end{tabular}

\section{RESULTS AND DISCUSSION}

Calving management and care of new-born calf

Jersey crosses were the most prominent (50.7\%) category of cattle followed by Friesian (47.9\%) and Ayrshire (1.4\%) crosses in Mid-Country area. Separate calving pens are essential in cattle management in order to ensure hygiene, comfort and minimize the stress of dam and new-born during calving (Svensson et al., 2003). Provision of calving pens and naval disinfections after birth were not practised by any of the farmers surveyed. Evidence in the literature have proved that calving with a group setting increased risk of the calf being suffering from diarrhoea (Frank and Kaneene, 1993), respiratory problems (Svensson et al., 2003), and the risk of Salmonella infections (Losinger et al., 1995). According to Vasseur et al. (2010), sick cows in calving area were a source of disease for the new-born. Nevertheless, after the birth, the calf is at risk of getting infections through naval, nostrils and mouth from calving environment (Mee, 2013). Thus, keep a close attention on new-borns is a critical aspect in calf management. Although technological monitoring system was not applied for calving area observations in the present study, the information gathered confirmed that farmers 
visited cows only two times, once each during day and night. The night visit was paid for cows who were expected to calve. Therefore, lack of calving pens and naval disinfection were a significant welfare risk for both cow and calf.

\section{Colostrum management}

From a welfare perspective, colostrum is considered an essential to develop normal physiological and natural behaviour of calf's life (Stull and Reynolds, 2008) as colostrum consists of immunoglobulin, nutrients, cytokines and growth factors (Conneely, 2013) that are most important for calf health and survival (Godden, 2008). Optimum absorption of immunoglobulin occurs within four hours after birth (Weaver et al., 2000) and factors such as method and volume of colostrum feeding, immunoglobulin concentration (Charlton, 2009), and age of dam also effect on absorption. The survey results depicted that, $97.3 \%$ of farmers fed their calves within one hour of birth, and others $(2.3 \%)$ within two hours of birth. Although the timing of first colostrum was satisfied, leaving calves with the dam to nurse colostrum $(99.5 \%)$ was a major issue since the required quality and quantity of colostrum is difficult to measure. The study by Beam et al., (2009) demonstrated that failure of passive transfer of immunity was high through inadequate quantity of colostrums. Pooled colostrum or mixing together colostrum from various sources which was not recommended due to increase opportunities for bacterial contaminations (Weaver et al., 2000) was practised only in one farm in the area.

\section{Calf-Dam separation}

Immediate calf-dam separation within short period of birth is recommended to reduce the stress due to cow-calf bond (Weary and Chua 2000), for better supervision of colostrum (Flower and Weary, 2001), to decrease risk of exposure to environmental pathogens and disease transfer (Windsor and Whittington, 2010) and for better income (Marcé et al., 2011). According to the current study, delayed separation time ( $>24$ hours from birth) was the most common practice among farmers (93.0\%) whereas $2.7 \%$ of farmers practiced the separation before $24 \mathrm{hrs}$ and only two farmers separate calves within two hours. However, the least stressful routine practice for both cow and calf is the important factor for which immediate separation would be a solution, but least practiced in Mid-Country, Sri Lanka. On the other hand, the European Food Safety Authority (2006) identified separation of calf from the dam as a main risk for calf welfare because of the lack of maternal care. Late separation is generally recommended due to benefits such as improving natural behaviour with emotional benefits for both dam and calf (Marcé et al., 2011; Daros et al., 2014), better weight gain, improving udder and uterine health (Flower and Weary, 2001) of cows.

\section{Painful procedures}

For identification of calves, all farmers used ear tags but practiced only for female calves with the help of a veterinary surgeon. No particular age for ear tagging was followed by farmers, but commonly done within the age of 2-4 months. According to Quigley et al., (1996), practicing an identification method as early as possible is important from the point of view of new-born caring and individual follow up. Painful procedures such as disbudding, dehorning, teat removal and castration were not regularly carried out in the surveyed area. Only one farmer in the current study found practicing disbudding of calves at the age of two months by the farmer himself using a hot iron without prior application of local anaesthetics. However, some medicines were given following the process as pain killers. As described by Stafford and Mellor, (2005), 
dehorning might be useful to reduce the risk of injuries for both human and other animals and can be practiced with local anaesthetics and long-lasting analgesics to reduce pain during and after the operation (Theurer et al., 2012).

\section{Calf housing}

According to Curtis et al. (2016), risk of diseases, negative effects of welfare and feeding was increased due to group housing when calves were reared in cow barns which was the widely practiced housing method (96.2\%) found in Mid-Country Sri Lanka. Only $3.8 \%$ of farms used individual pens for calf rearing. Housing should allow calves to easily lie down, stand up, turn around and adopt normal resting behaviours (Guatteo et al., 2010). Majority of farms (90.1\%) had smooth cement/rough concrete flooring, and few had gravel/soil (6.0\%) and wood material (3.9\%). Bedding materials for calves were used only by $10.4 \%$ of farmers used either Grass (78.9\%) or Wood shavings/Straw (21.1\%). Prevalence of dirty (40.7\%), hoof damageable (45.6\%), and slippery floors (75.8\%) were noticed as negatively affecting factors on calf welfare. Generally, considerable percentages of calves $(74.2 \%)$ in the Mid-Country did not receive sufficient space for the lying area and were tied in the walking area or space restricted area in cattle shed. Calves were allowed for outdoor grazing by $12 \%$ of farmers for few hours (1-2 hrs) per day, even though intensive management system was practiced. This could reduce the risk of transmitting of air-born diseases by sharing of the same air space within the barn (Vasseur et al., 2010). In contrast, outdoor grazing without any shade or under intensive sunlight could increase the skin temperature of calves. In the current study, the skin temperature of calves in outdoor grazing was slightly higher $\left(32.07{ }^{\circ} \mathrm{C}\right)$ than that of calves in the indoor condition $\left(31.30^{\circ} \mathrm{C}\right)$. The study by Eddy et al.,
(2001), emphasized that skin temperature directly reflects underlying circulation and tissue metabolism and do alternations to the sympathetic nervous system. Therefore, prior to letting the calves for outdoor grazing, attention needs to be paid on their skin temperature.

\section{Hock wounds and hoof temperature}

Thermography scans were evaluated to identify hock wounds by measuring heat emitted from the surface (Gloster et al., 2011). Accordingly the prevalence of hock wounds of calves in the present study was $83.4 \%$. The number of hock wounds per calf was positively and significantly correlated $(\mathrm{P}<0.05)$ with bed length, width and area $(\mathrm{r}=$ $0.181,0.234,0.207$, respectively, and floor slipperiness was positively and significantly $(\mathrm{P}<0.001)$ correlated with prevalence of hock wounds $(r=0.244)$. Wound severity was also significant correlated $(\mathrm{P}<0.05)$ with floor slipperiness where unit increasing of slipperiness, increased severity of wounds by 31.1\%. In 2017, Sadiq et al., also observed high number of severely wounded cows on slippery floors compared those on non-slippery floors. Floor dirtiness also significantly associated with severity of wounds $(\mathrm{P}<0.001)$ and a unit increase of floor dirtiness augmented severity of wounds by $17.2 \%$. Hoof temperature was significantly $(\mathrm{P}<0.05)$ associated with type of floor. The floors with cracks and hoof damageable floors showed calves with high hoof temperature. This may be due to bacterial infections of claw and hoof injuries in cracks positive environment (Hultgren and Bergsten, 2001; Gloster et al., 2011).

\section{Calf feeding and weaning}

Milk feeding of calves generally contributes to high growth rates during the pre-weaning period and improved production and health in adult life (Curtis et al., 2016). Dam-fed milk cannot be measured and controlled. 
Therefore, it might leads to hunger or overfed conditions. Only $2.2 \%$ of farms used bucket/bottle feeding of fresh whole milk (4 L/ calf / day) in two meals during their preweaned period. Dry feed availability is important for rumen development. Nevertheless, low intakes restrict the weight gain, nutrient intake and will create problems in ruminal digestibility and weaning transition (Lorenz et al., 2011). Although it was recommended to provide access to roughage and concentrates to calf within 10-14 days of age in Sri Lanka, (DAPH, 2014), the present study revealed that only $19.8 \%$ of farmers in the study area practised it. It was also revealed in the present study that adequate amounts of concentrates compared to the recommended amounts were given to claves. Water supplementation for claves should be started from the date of birth (DAPH, 2014). However, none of the farmers followed this recommendation and only $6.6 \%$ of farmers started water supplementation within a week, and others even later. Weaning off milk is the first feed transmission of calves (Vasseur et al., 2010) and is a very vital time period because of the stress that takes place during this time (Weaver et al., 2000). Weaning at the age of three months was the most applicable weaning age among dairy farmers (44.0\%) in Mid-Country, Sri Lanka whereas $4.9 \%$ of farmers weaned their calves before three months of age. Gradual weaning which is the recommended practice (Daros et al., 2014) was adopted by all the farmers surveyed.

According to the present findings, claves found in the study area were underweight compared to standard values (DAPH, 2014) as shown in Figure 1.

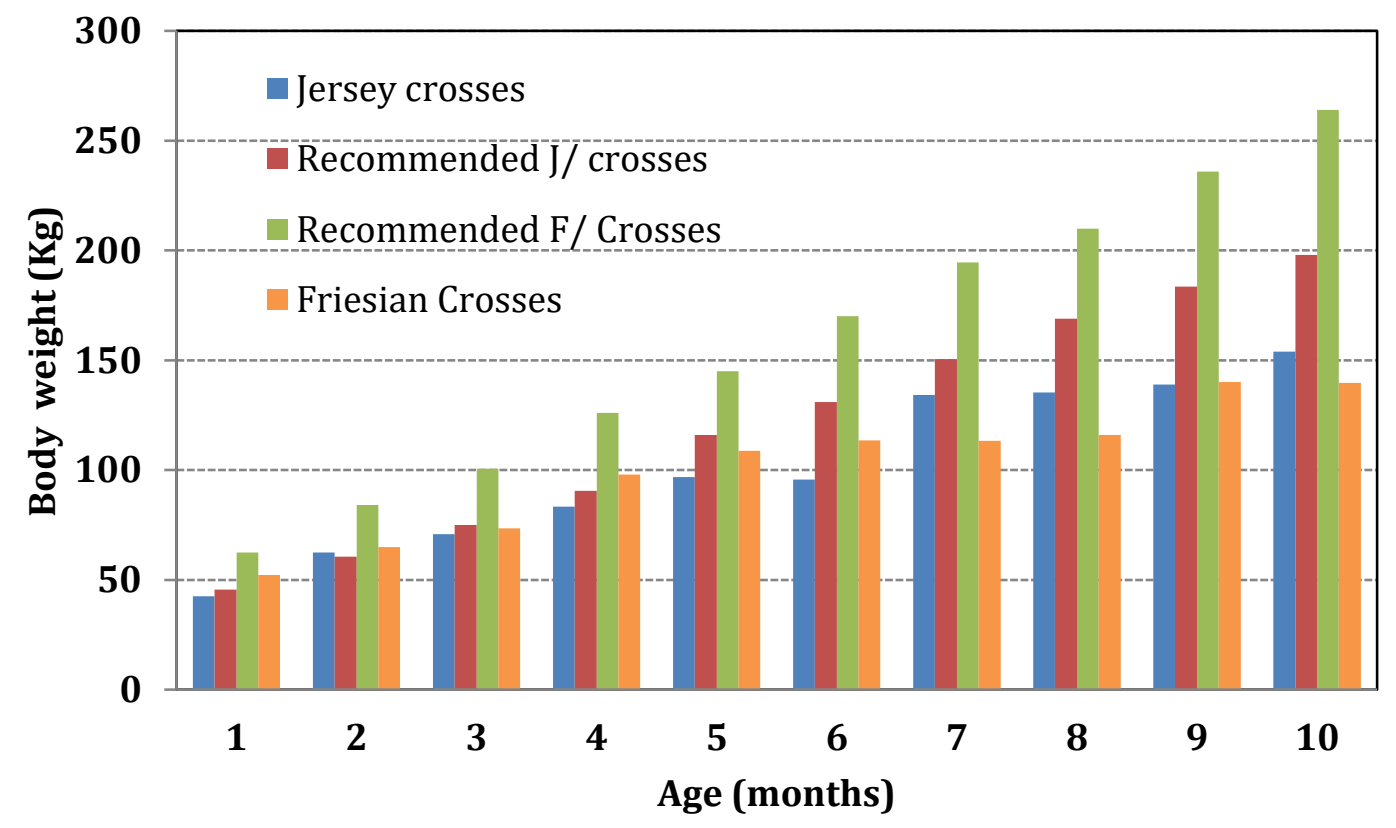

Figure 1: Comparison of bodyweight of calves with recommended values upto 10 months of age

Improper feeding practices, which negatively influences on feed intake, such as absence of separate feeder for calves (95\%), sharing of adult cattle feeder and high feeder heights (72.1\%) observed in the present study could be the reasons for underweighted-claves. Calves also might be underweight due to diarrhoea (Lorenz et al., 2011) and improper weaning practices (Sweeney et al., 2010).

\section{Calf handling, diseases and mortality}

Relationship between attitudes and behaviour of stock person towards the calf had affected on welfare and productivity of animal (Breuer 
et al., 2000). It was observed in the present study that the farmers in the study area paid good attention to calf handling and there was no evidence of using electric prods, hitting and kicking. Further veterinarian was immediately informed by majority of farmers (97.3\%) in case of sickness.

Calf diseases and mortality have short-term and long-term detrimental effects on the performance of a dairy farm and exposure to a contaminated environment enable the transmission of pathogens (Guatteo et al., 2010). Parasitic diseases were common in $43.8 \%$ of farms in the study area, and followed by diarrhoea (28.1\%), bloating (6.2\%), naval infections $(1.1 \%)$ and respiratory problems (1.1\%). Guatteo et al., (2010) had identified that inadequate ventilation and air temperature influenced the incidences of infectious diseases in calves. Reporting the influence of low temperature inside the shed Curtis et al., (2016), reported that it increased the risk factor for diseases specially for calves under three weeks of age. According to the present survey, $23.1 \%$ and $30.2 \%$ of farms had poor ventilation and poor light condition inside sheds, respectively.

Roofing materials used by farmers vary from asbestos (28.6\%), tin (68.1\%), polythene $(2.7 \%)$ to tile $(0.5 \%)$. However, a major concern was that $35.7 \%$ of farms had leaking roofs which might have contributed to the increased prevalence of diseases such as Diarrhea 32.4\%, Parasitic diseases 38.2\% and Bloating 8.8\% compared to the prevalence of those with roofs without leaks $(26.6 \%, 33.1 \%$. $6.6 \%$, respectively).

Calf deaths were recorded in $28.0 \%$ of farms and in $39.2 \%$ of the farms mortality rate was higher than $5 \%$ per year. Several key areas were identified as causes for calf mortality, such as the prevalence of diseases (39.2\%), improper flooring (84.3\%), poor knowledge of calf welfare $(68.6 \%)$ and nutrition $(72.5 \%)$. Similarly, poor/inadequate quality housing
(Curtis et al., 2016), poor management practices and disease prevalence (Renaud et al., 2018) were also recorded by researches in relation to calf mortality.

\section{The fate of male calves}

Many western countries treat male and female calves differently. They paid less attention and care for male calves than females. Ellingsen $e t$ al., (2014) had revealed that male calves were fed by less quality and insufficient quantity of colostrum supplement by farmers and easily vulnerable to diseases compared to females as they do not receive proper care and medical attention (Renaud et al., 2018). In addition, other risk factors were also found such as culling the - male calf (Cardoso et al., 2017), selling them for veal at $2^{\text {nd }}$ and $4^{\text {th }}$ week after birth (Marcé et al., 2011) and prevalence of high mortality rate (Pritchard et al., 2008). Compared to them welfare and ethical consideration of Sri Lankan farmers towards male calves were comparatively high. Majority of farmers (89.6\%) sold their male calves after six months of age and treated them equal to females $(99.5 \%)$ by providing all supplements including colostrum, concentrates, vitamins and milk feeding. Mean weaning age of male calves was 3.8+1.4 months with average body weight of $122.9 \pm 31.9 \mathrm{~kg}$, and average concentrate intake was $0.55 \pm 0.25 \mathrm{~kg} /$ day/ calf. Veterinary care was immediately sought by $96.5 \%$ of farmers in case of sickness.

\section{Age group of farmers and welfare attitudes}

Calves are sensitive animals and positive attitudes of a farmer could lower the mortality rate (Lensink et al., 2000). Low levels of withdrawal are also associated with positive contact (petting, touching, talking in a friendly manner) between calves and handlers (Ellingsen et al., 2014). In the present study, welfare knowledge of farmers (39.5\%) significantly associated with floor cleanliness $(\mathrm{P}<0.001)$ and nutritional requirements 
$(\mathrm{P}<0.001)$. Farmers with positive welfare attitudes $(38.6 \%)$ showed good caring and management towards calves indicated by zero mortality $(77.5 \%)$, free from diseases $(67.6 \%)$, shed with no leaking roofs $(73.2 \%)$, safe flooring $(62.0 \%)$, clean floors $(76.0 \%)$, nonslippery floors (32.4\%), proper ventilation (91.6\%) and sufficient light inside shed (80.3\%) compared with farmers with unhelpful welfare attitudes.

Age group of farmers also contributed to welfare attitudes. Youths (18-30 years) had higher percentage of proper flooring $(76.9 \%)$, proper light/ventilation inside the shed (100\%), use of calf pen (21.4\%), concentrate/roughage access within 10-14 days (61.0\%), low mortality (zero) and good welfare and nutritional knowledge (64.3\%) than shown by adults (31-60 years) and senior farmers (>60years). In stockpersonship, simple fine liaison was not recommended and, other professional and personal components, such as appropriate knowledge, technical skills, observational abilities and time availability are also considered (Lensink et al., 2001). This emphasized that seniority or experience level itself cannot improve calf welfare and it was essential to refine farmers with proper knowledge.

\section{CONCLUSIONS}

Several calf management practices were identified as risk factors associated with calf welfare. Poor calving and calf management practices such as not using calving pens, not practicing naval disinfection for new-borns, absence of calf pen, dam-fed colostrum feeding system were most prominent in Mid-Country dairy farms in Sri Lanka. Improper feeding management practices and lack of knowledge on welfare leading to underweight and high mortality among calves. Unacceptable flooring conditions such as slipperiness, poor cleanliness and hoof damageable floors significantly associated with prevalence and severity of hock wounds and high hoof temperature. However, an adequate amount of concentrates were supplied to calves with equal caring for both male and female calves. Young farmers followed proper management practices compared to adult and senior farmers. Awareness and training on good management and welfare practices to minimize the risk factors in dairy industry could easily be practiced for dairy farmers in Mid country area.

\section{ACKNOWLEDGEMENTS}

The National Research Council of Sri Lanka (Grant no. NRC - TO -14-10)

\section{REFERENCES}

Bandara, R. M. A. S., Rajapaksha, S. M., Munasinghe, M. A. J. P.,Wijerathna, K. M. N., \& Kumara, P. K. M. P. (2015). Welfare issues of calf management practices in small scale dairy farms, Ratnapura District, Sri Lanka. International Journal of Livestock Production, 6(4), 52-56. doi: 10.5897/IJLP2014.0210

Beam, A. L., Lombard, J. E., Kopral, C. A., Garber, L. P., Winter, A. L., Hicks, J. A. and Schiater, J. L. (2009). Prevalence of failure of passive transfer of immunity in newborn heifer calves and associated management practices on US dairy operations. Journal of Dairy Science. 92(8), 3973-3980. doi: 1 0.31 68/jds.20092225

Breuer, K., Hemsworth, P. H. and Barnett, J. L. (2000). Behavioural response to humans and the productivity of commercial dairy cows. Applied Animal Behaviour Science. 66,273288.

Cardoso, C. S., Keyserlingk, M. A. G. Von and Jos, M. (2017). Brazilian Citizens: Expectations Regarding Dairy Cattle Welfare and 
Awareness of Contentious Practices. Animals. 7,89. doi:10.3390/ani7120089

Charlton, S. J. (2009). Calf Rearing Guide, Leicestershire, LE65 1WN England.

Conneely, M., D. Berry, R. Sayers, J. Murphy, I. Lorenz, M. L. Doherty and E. Kennedy. (2013). Factors associated with the concentration of immunoglobulin $g$ in the colostrum of dairy cows. Animals, 7, 1824- 1832.

Curtis, G. C., Argo, C. M., Jones, D. and White, D. H. G. (2016). Impact of feeding and housing systems on disease incidence in dairy calves. Veterinary Record. 179(20), 512. doi: 10.1136/vr.103895

Daros, R. R., Costa, J. H. C., Keyserlingk, M. A. G., tzel, M. J. H. and Weary, D. M. (2014). Separation from the dam causes negative judgement bias in dairy calves. PLoS ONE. 9(5), 5-9.doi: 10.1371/journal.pone. 0098429

DAPH (2004). Good Agricultural Practices in Dairying. Livestock Planning and Economics Division Department of Animal Production and Health, Gatambe, Peradeniya.

DAPH (2009). Estimation of Cost of Production of Milk in Different Agro Climatic Zones of Sri Lanka. Livestock Planning and Economics Division Department of Animal Production and Health, Gatambe, Peradeniya. $1-21$.

DEFRA (2003). Codes of Recommendations for Welfare of Livestock: Cattle. Department for Environment, Food and Rural Affairs. England.

Eddy, A. L., Van Hoogmoed, L. M. and Snyder, J. R. (2001). The role of thermography in the management of equine lameness. Veterinary Journal. 162(3),172-181. doi:10.1053/tvjl.
2001.0618

EFSA (2006) European Food Safety Authority, Italy, EFSA Panel on Animal.Health and Welfare, Scientific Opinion on the welfare of cattle kept for beef production and the welfare in intensive calf farming systems. EFSA Journal. 10 (5), 2669.

Ellingsen, K., Colemanb, G. J., Lunda, V. and Mejdell, C. M. (2014). Using qualitative behaviour assessment to explore the link between stockperson behaviour and dairy calf behaviour. Applied Animal Behaviour Science.153,10-17. doi: 10.1016/j.applanim. 2014.01.011

Flower, F. and Weary, D. (2001). Effects of early separation on the dairy cow and calf. Applied Animal Behavior Science. 70, 275284.

Frank, N. A. and Kaneene, J. N. (1993). Management risk factors associated with calf diarrhea in Michigan dairy herds. Journal of Dairy Science 76, 1313-1323.

Gloster, J., Ebert, K., Gubbins, S., Bashiruddin, J. and Paton, D. J. (2011). Normal variation in thermal radiated temperature in cattle: Implications for foot-and-mouth disease detection. BMC Veterinary Research. 7(1),73. doi: 10.1186/1746-6148-7-73

Godden, S. (2008). Colostrum management for dairy calves. Veterinary Clinic North America: Food Anim. Practice. 24, 19-39. doi: 10.1016/j.cvfa.2007.10.005

Guatteo, R., Marce, C. and Fourichon, C. (2010). Dairy calf housing systems across Europe and risk for calf infectious diseases.Animals.4(9),1588-1596. doi: 10. 1017/S1751731110000650 
Hultgren, J. and Bergsten, C. (2001). Effects of a rubber-slatted fooring system on cleanliness and foot health in tied dairy cows. Journal of Dairy Research. 52,75-89.

Keyserlingk, M. A. G., Rushen, J., de Passillé, A. M., Weary, D. M. (2009). Invited review: The welfare of dairy cattle - Key concepts and the role of science. Journal of Dairy Science. 92(9), 4101-4111. doi: 10.3168/jds.2009-2326

Lensink, B. J., Veissier, I. and Florand, L. (2001). The farmers' in uence on calves' behaviour, health and production of a veal unit. Animal Science. 72,105-116.

Lensink, J., Boissy, A. and Veissier, I. (2000). The relationship between farmers' attitude and behaviour towards calves, and productivity of veal units. Annales de Zootechnie. 49(4),313-327. doi: 10.1051/ animres:2000122

Lorenz, I., Fagan, J. and More, S. J. (2011). Calf health from birth to weaning. II . Management of diarrhoea in pre-weaned calves. 64(9),1-6.

Losinger, W. C. and Heinrichs, A. J. (1995). Management practices associated with high mortality among preweaned dairy heifers. Journal Dairy Research. 64,1-11.

Marcé, C., Ezannoa, P., Seegersa, H., Pfeifferb, H. D. U. and Fourichon, C. (2011). Within-herd contact structure and transmission of Mycobacterium avium subspecies paratuberculosis in a persistently infected dairy cattle herd. Preventive Veterinary Medicine. 100,116-125. doi: 10.1016/ j.prevetmed.2011.02.004

Mee, J. F.(2013). Why do so many calves die on modern dairy farms and what can we do about Calf Welfare in the future.Animals.3,10361057. doi: $10.3390 /$ ani3041036
Pritchard, D. G., Pfeiffer, D. U., Jones, E. and Mawdsley, J. J. (2008). Calf mortality as a welfare indicator on British cattle farms. The Veterinary Journal.176,177-181. doi: 10.1016/j.tvjl.2007.02.006

Quigley, J. D., Nyabadza, C. S. T., Benedictus, G. and Brand, A. (1996). Monitoring replacement rearing.75-102.

Renaud, D. L., Kelton, D. F., LeBlanc, S. J., Haley, D. M. and Duffield, T. F. (2018). Calf management risk factors on dairy farms associated with male calf mortality on veal farms. Journal of Dairy Science. 101, 1-10. doi: 10.3168/jds.2017-13578

Sadiq, M. B., Mossadeq, W. M. S., Mansor, S. and Hussain, S. S. S. (2017). Association between lameness and indicators of dairy cow welfare based on locomotion scoring, body and hock condition, leg hygiene and lying behavior. Animals. 7(11),79. doi: 10.3390/ani7110079

Stafford, K. J. and Mellor, D. J.(2005). Dehorning and disbudding distress and its alleviation in calves. Veterinary Journal. 169 (3), 337-349. doi: 10.1016/j.tvjl. 2004. 02.005

Stull, C. and Reynolds, J. (2008). Calf Welfare. Vet Clin Ani Pra.24, 191-203. doi: 10.1016/j.cvfa.2007.12.001

Svensson, C., Lundborg, K., Emanuelson, U. and Olsson, S. O. (2003). Morbidity in Swedish dairy calves from birth to 90 days of age and individual calf-level risk factors for infectious diseases. Veterinary Medicine. 58,179-197.

Sweeney, B., Rushen, D., Weary, D. M. and Passille, A. M. (2010). Duration of weaning, starter intake, and weight gain of dairy calves fed large amounts of milk. Journal of Dairy Science, 93 :148-152. doi: 10.3168/jds.92427 
Theurer, M. E., White, B. J., Coetzee, J. F., Edwards, L. N., Mosher, R. A. and Cull, C. A. (2012). Assessment of behavioral changes associated with oral meloxicam administration at time of dehorning in calves using a remote triangulation device and accelerometers. BMC Veterinary Research. 8, 48.doi: 10.1186/1746-6148-8-48

USDA-NAHMS (2011). Dairy Heifer-raiser. National Animal Health Monitoring System. Animal and Plant Health Inspection Service. Fort Collins.

USDA-APHIS (2014). General Dairy Management Questionnaire - January. Animal and Plant Health Inspection Service. Fort Collins.

Vasseur, E. Borderas, F., Cue, R. I., Lefebvre, D., Pellerin, D. and Rushen, J. (2010). A survey of dairy calf management practices in Canada that affect animal welfare. Journal of Dairy Science, 93(3), 1307-1316. doi: 10.3168/ jds.2009-2429

Weary, D. M. (2001). Calf Management:
Improving Calf Welfare and Production. Advances in Dairy Technology. 13, 107-118.

Weary, D. M. and Chua, B. (2000). Effects of early separation on the dairy cow and calf. Applied Animal Behaviour Science. 69, 177188.

Weaver, D. M., Tyler, J. W., VanMetre, D. C., Hostetler, D. E. and Barrington, G. M. (2000). Passive transfer of colostral immunoglobulins in calves. Journal of Veterinary Internal Medicine. 14,569-577.doi: 10.1892/08916640

Windsor, P. A. and Whittington, R. J. (2010). Evidence for age susceptibility of cattle to Johne' s disease. The Veterinary Journal. 184(1), 37-44 doi: 10.1016/j.tvjl. 2009. 01.007 